1990

\title{
Model studies of shallow common-offset seismic data
}

Thomas H. Wilson

Follow this and additional works at: https://researchrepository.wvu.edu/faculty_publications

\section{Digital Commons Citation}

Wilson, Thomas H., "Model studies of shallow common-offset seismic data" (1990). Faculty Scholarship. 233.

https://researchrepository.wvu.edu/faculty_publications/233 


\title{
Model studies of shallow common-offset seismic data
}

\author{
Thomas H. Wilson*
}

For simplicity, optimum-window common-offset data-acquisition procedures are frequently employed to collect near-surface, high-resolution, seismic reflection data. However, because of large incidence angles, interpretations of the data often cannot be evaluated accurately using zero-offset simulations alone.

Common-offset hammer seismic data collected in the central Appalachian plateau province of West Virginia are examined in this paper. Synthetic shot records using a minimum-phase wavelet estimated from the data and subsurface acoustic properties derived from full-waveform and other geophysical logs are used to simulate the offset seismic response of near-surface, coal-bearing Pennsylvanian aged rocks. Zoeppritz equations are used to model amplitudes.

This study indicates that offset simulations may be required to determine the origins of events observed at a given offset. Offset simulations also help determine whether amplitude variations with offset have a significant effect on the appearance of events observed at the optimum offset. The offset seismic response is significantly different from the zero-offset response for reflections arising from depths less than about twothirds of the offset distance; for greater depths, zerooffset simulations adequately approximate the offset response.

\section{INTRODUCTION}

Common-offset optimum-window data (Hunter et al., 1984, 1985; Dobecki and Romig, 1985; Dobecki and Larson, 1987) were collected to examine the effects of longwall mining on the seismic properties of the cover rocks (Wilson et al., 1988). The mine site is located in the central Appalachian plateau province of West Virginia. Data were recorded using Bison Instrument's GeoPro 8012A portable 12-channel engineering seismograph with an input passband generally between 75 and $475 \mathrm{~Hz}$; a $16 \mathrm{lb}(7.3 \mathrm{~kg})$ sledgehammer was used as a source. Geophones with $60 \mathrm{~Hz}$ natural frequencies were used.

We have found (Wilson et al., 1988; He and Wilson, 1989) that while common-offset data generally have lower signalto-noise ratios than stacked data, changes in the seismic characteristics of the subsurface can be related directly to the volume of rock along a single source-receiver pathway, allowing one to observe changes in subsurface physical properties that are restricted in distribution. Because these changes are not always associated with a reflection point, but occur along reflection pathways, their effect is generally reduced or eliminated by the averaging process of stack. These changes may affect the appearance and continuity of deeper reflection data but are of interest in engineering and hydrologic applications since they may indicate the presence of voids, intensely fractured areas, and minor stratigraphic variability in the overburden and bedrock.

Common-midpoint (CMP) record sections are often modeled and interpreted under the assumption that a stacked trace corresponds to a coincident seurce and receiver, but the common-offset record clearly represents an offsetdependent seismic response. The necessity for offset modeling, however, depends primarily on Poisson's ratios of near-surface materials and the observed range of reflection incidence angles.

\section{ACOUSTIC PROPERTIES}

The cover rocks above the Redstone coal (the mined seam), aside from a thin veneer of alluvium and weathered bedrock, consist primarily of thinly bedded Pennsylvanian aged sedimentary rocks (Figure 1 ). $P$-wave velocities in these rocks, ranging from approximately 8000 to $15000 \mathrm{ft} / \mathrm{s}$ (2438 to $4572 \mathrm{~m} / \mathrm{s}$ ), were derived from several sources, including (1) a sonic $\log$, (2) crossplot-derived relationships between sonic and other logs run in both the dry and water-filled parts of the hole, and (3) head-wave or wideangle reflection moveout measured in noise tests. Velocity variations presented in Figure 1 are averaged and blocked to portray only major differences.

Manuscript received by the Editor July 26, 1988; revised manuscript received October 6, 1989.

${ }^{*}$ Department of Geology and Geography, West Virginia University, Morgantown, WV 26506.

(C) 1990 Society of Exploration Geophysicists. All rights reserved. 

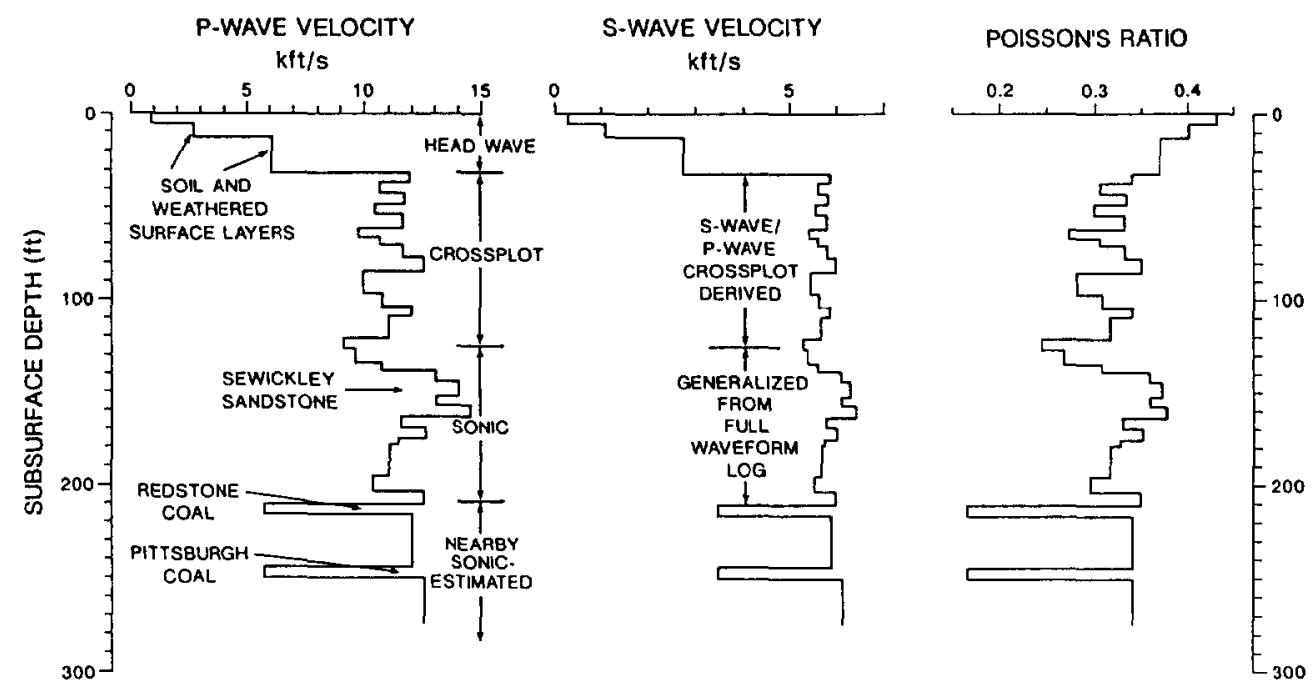

FIG. 1. P-wave, $S$-wave, and Poisson's ratios used to compute synthetic shot records.

Shear-wave velocities (Figure 1) in the lower half of the borehole were derived from a full-waveform log. Shear-wave velocities in the upper half of the borehole were assigned using a crossplot relationship between compressional- and shear-wave velocities in the lower half of the borehole. Shear-wave velocities for the upper $32 \mathrm{ft}(9.8 \mathrm{~m})$ and for the coals are based on reported values of Poisson's ratios (Figure 1) for these or similar intervals in other areas. High Poisson's ratios characterize near-surface weathered layers (Szelwis and Behle, 1987). The near-surface soil layer and weathered bedrock were assigned Poisson's ratios of between 0.43 and 0.37 (Figure 1). Coal shear-wave velocities were then back-calculated from the assumed Poisson's ratio of 0.16 (Rzhevsky and Novik, 1971) and corresponding compressional-wave velocities for these intervals (Figure 1). Poisson's ratios over the remainder of the section (Figure 1) were calculated directly from the crossplot and fullwaveform-derived compressional- and shear-wave velocities.

\section{SEISMIC DATA CHARACTERISTICS}

\section{The optimum offset}

Hunter and Pullan (1989) define an optimum window as the range of offsets that allows the reflection from the target horizon to be observed with minimum interference from signal-generated noise (see also Hunter et al., 1984). The choice of optimum offset for common-offset data acquisition is based on noise tests, e.g., the hammer seismic data of Figure 2. Several different types of seismic events are present in Figure 2. Event $A$ is a direct arrival, traveling in the near surface with a velocity of approximately $4000 \mathrm{ft} / \mathrm{s}$ $(1220 \mathrm{~m} / \mathrm{s})$. Events $\mathrm{B}$ and $\mathrm{C}$ are generally considered to be head waves. Event B has an apparent velocity of approximately $9300 \mathrm{ft} / \mathrm{s}(2830 \mathrm{~m} / \mathrm{s})$ and event $\mathrm{C}, 13600 \mathrm{ft} / \mathrm{s}(4140$ $\mathrm{m} / \mathrm{s}$ ). Based on head-wave relationships, the refracting surface associated with event $B$ is calculated to be approximately $10 \mathrm{ft}(3 \mathrm{~m})$ beneath the surface, while that associated with event $\mathrm{C}$ is calculated to lie approximately $47 \mathrm{ft}(14 \mathrm{~m})$ beneath the surface. The interval associated with event $C$ is the $13 \mathrm{ft}(4 \mathrm{~m})$ thick Pennsylvanian-aged Sewickley sandstone. Results of model studies presented below suggest that event $\mathrm{D}$ is a reflection from the Redstone coal and event $\mathrm{E}$ is a reflection from the Pittsburgh coal. Linear events marked $\mathrm{F}$ with velocities of approximately $4400 \mathrm{ft} / \mathrm{s}(1340 \mathrm{~m} / \mathrm{s})$ are of uncertain origin. A low-velocity Rayleigh wave and air wave are also visible in the record.

The optimum window for recording shallow reflections in the area of the noise test (Figure 2) extends from approximately $110 \mathrm{ft}(33 \mathrm{~m})$ to $230 \mathrm{ft}(70 \mathrm{~m})$. Near-source linear-noise events, such as the ground-coupled air wave, Rayleigh wave, and the events marked $F$, obscure deeper reflection events that might be present on shorter offsets in the record (Figure 2). Signal amplitude at offsets greater than $230 \mathrm{ft}$ (70 $\mathrm{m})$ drops almost to the level of the background noise. The $150 \mathrm{ft}(46 \mathrm{~m})$ offset is suitable as an optimum offset, since (1) the signal-to-noise ratio is high at this offset, (2) the

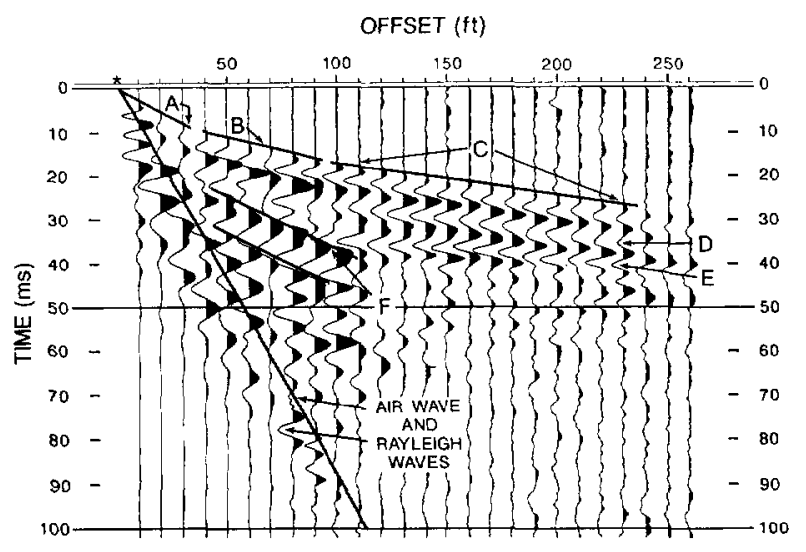

FIG. 2. Line 1 noise test: near-source receiver offset is $10 \mathrm{ft}$ $(3 \mathrm{~m})$ and the geophone separation is $10 \mathrm{ft}(3 \mathrm{~m})$. 
reflections from the Redstone and Pittsburgh coals are coherent across this offset, and (3) there is little possibility of interference from near-source linear noise.

\section{Resolution}

The noise test shown in Figure 2 is one of the best from the survey area. The peak frequency in this record is approximately $190 \mathrm{~Hz}$. The noise test shown in Figure 3 is more typical of the data collected in the area. The minimum-phase wavelet used in the simulations was derived from the windowed average autocorrelation of the traces in Figure 3 and has a peak frequency of approximately $140 \mathrm{~Hz}$.

In general, the top and bottom of a layer can be resolved if the interval transit time through the layer is greater than or equal to one-fourth the dominant period of the seismic wavelet (Widess, 1973; Sheriff, 1977). The wavelet used in the following model studies (Figure 3) has a peak-to-trough time separation (half-period) of $3.6 \mathrm{~ms}$. Hence, the top and base of the coals in this area with velocities of approximately $5500 \mathrm{ft} / \mathrm{s}(1680 \mathrm{~m} / \mathrm{s})$ are resolvable if they are thicker than 10 $\mathrm{ft}(3 \mathrm{~m})$. The majority of the Pennsylvanian-aged rocks in the coal-bearing interval of the study area, however, have much higher velocities, ranging from approximately 9000 to 15000 $\mathrm{ft} / \mathrm{s}(2700$ to $4600 \mathrm{~m} / \mathrm{s})$. Hence, resolution thicknesses are generally greater, corresponding to 16 to $27 \mathrm{ft}(5$ to $8 \mathrm{~m})$, respectively.

The coals and sands in the near surface of the study area (Figure 1) are generally thinner than their resolution thicknesses. In addition, individual coals or sands in the subsurface are not isolated units, but are surrounded above and below by other thin intervals that also have significant impedance contrasts (Figure 1). Reflections from these closely spaced intervals further complicate the seismic response.

The limits of resolution are also a function of sourcereceiver offset distance. Shallow reflections, in particular, are viewed at large reflection angles, where interval traveltime differences are less than at normal incidence.

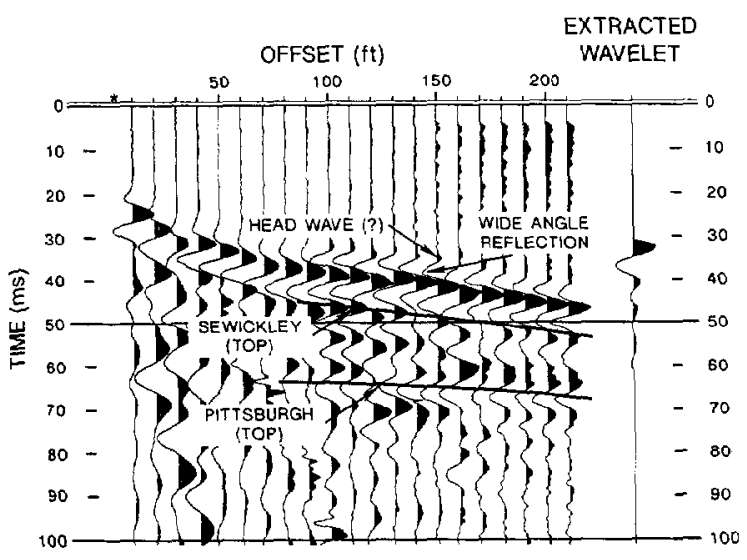

FIG. 3. Line 2 noise test. This noise test typifies the general quality of the data collected in the study area. The minimumphase wavelet estimated from the record is shown at the far right.

\section{SHALLOW MODEL DATA}

Model studies of two common-offset lines are presented. The zone of interest in this study extends from the surface to the Redstone and Pittsburgh coals (Figure 1). However, the surface elevation is quite variable in the study area so that along line 1 (Figure 4) the Redstone and Pittsburgh coals are only $120 \mathrm{ft}(37 \mathrm{~m})$ and $156 \mathrm{ft}(48 \mathrm{~m})$, respectively, beneath the surface, while along line 2 (Figure 5) the Redstone and Pittsburgh coals are $212 \mathrm{ft}(65 \mathrm{~m})$ and $245 \mathrm{ft}(75 \mathrm{~m})$, respectively, beneath the surface. Earlier arrivals interfere significantly with the wide-angle Redstone coal reflection on line I, whereas on line 2 the Redstone and Pittsburgh coal reflections are clearly separated from earlier events. The line 1 model study illustrates the upper limits of common-offset reflection profiling and interpretation in this area. The line 2 model study illustrates an approach to modeling and interpreting these intervals at greater depths.

\section{Line 1}

A generalized depth model for line 1 is presented in Figure 6. Surface elevation along line 1 is approximately $90 \mathrm{ft}(27 \mathrm{~m})$ below that along line 2 (Figure 1). Velocities used in the upper part of the model, down to and including the Sewickley sandstone, were derived from the direct arrivals and head waves or wide-angle reflections observed in the line 1 noise test (Figure 2). The detailed velocity variations shown in Figure 1 associated with the Sewickley sandstone and surrounding intervals along line 1 have little effect on the

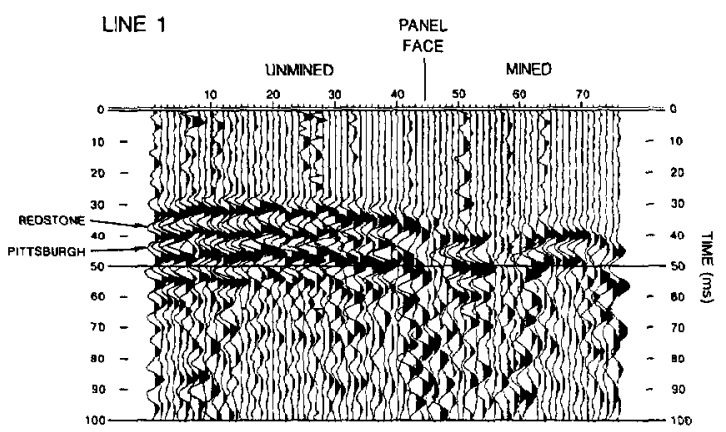

FiG. 4. Common-offset line 1 at an offset of $150 \mathrm{ft}(46 \mathrm{~m})$.

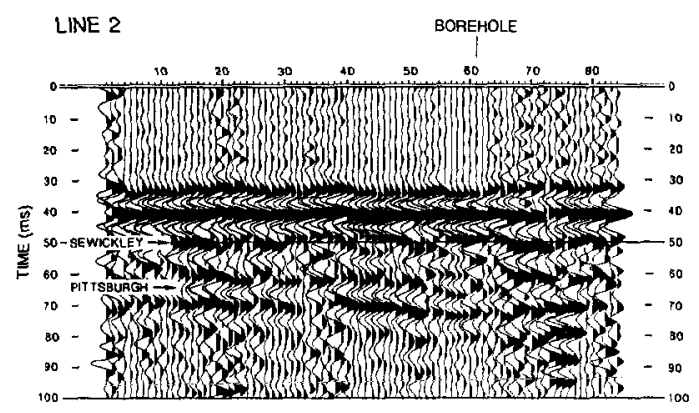

Fig. 5. Common-offset séismic line 2. 
wide-angle seismic response of this interval and, for simplicity, have been excluded from the model (Figure 6).

The synthetic common-shot record (Figure 7) is calculated using reflection ray tracing for traveltimes and Zoeppritz equations for reflection amplitudes. The many similarities and differences between the reflections-only synthetic seismegram and the neise test (Figure 2) previde useful information about the nature of subsurface wave propagation.

Direct arrival.-The wide-angle reflection event from the base of layer 1 forms a high-amplitude event on the synthetic

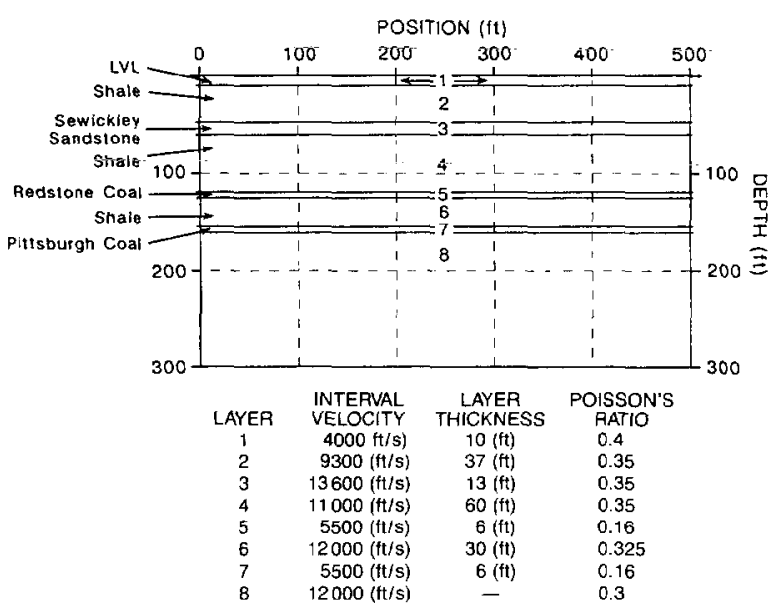

FIG. 6. Line 1 depth model.

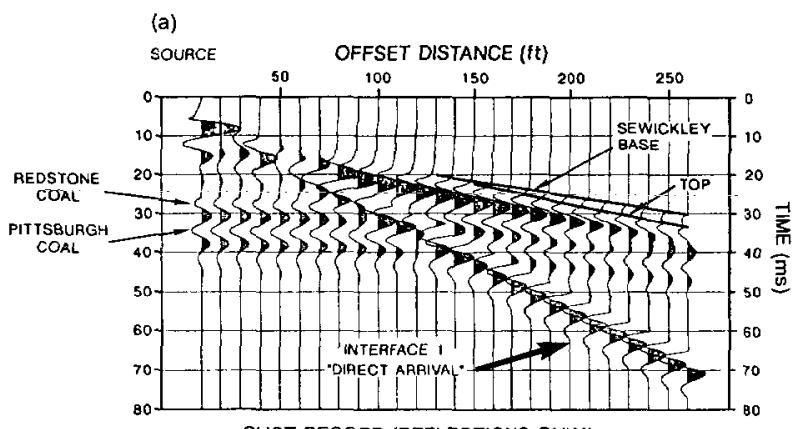

SHOT RECORD (REFLECTIONS ONLY)

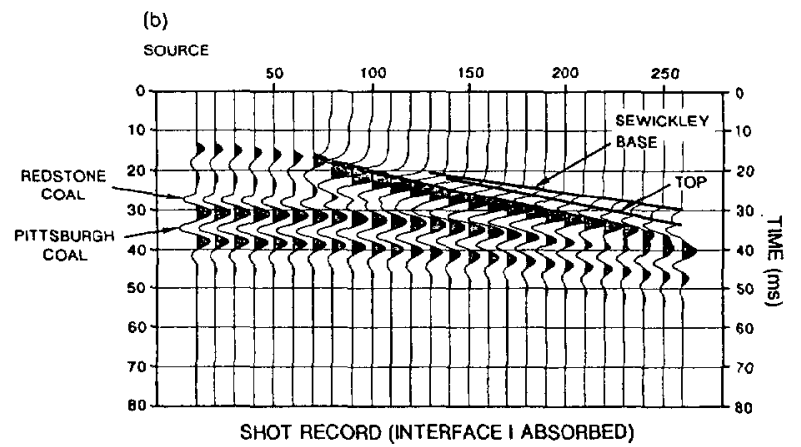

Fig. 7. Reflections only synthetic shot record for the line 1 depth model. (a) All reflections. (b) All reflections except that from the base of the near-surface. seismogram (Figure 7a). This event has a nearly linear moveout of $4000 \mathrm{ft} / \mathrm{s}(1220 \mathrm{~m} / \mathrm{s})$ for offsets greater than $10 \mathrm{ft}$ $(3 \mathrm{~m})$ and looks much like a direct arrival. In the line 1 noise test (Figure 2), however, the direct arrival is not observed beyond $10 \mathrm{ft}(3 \mathrm{~m})$ or so, indicating that the near-surface alluvium and weathered bedrock are highly absorptive. Also, with a highly absorptive near surface, near-surface multiples are not expected to be a problem. The synthetic seismogram was recalculated excluding the reflection from the base of the near-surface layer (Figure 7b), improving the similarity between the synthetic and actual data at offsets greater than $100 \mathrm{ft}(30 \mathrm{~m})$.

Head wave or wide-angle reflection?-The reflection from the base of the Sewickley sandstone on the synthetic seismogram (Figure 7) looks much like the apparent first arrivals observed in the noise test at offsets greater than $100 \mathrm{ft}(30 \mathrm{~m})$. The reflection coefficient from the base of the Sewickley sandstone is negative and produces a reflection that swings to the left (or negative) in this normal polarity display (Figure 7). The reflection from the top of the Sewickley sandstone, traveling with lower rms velocity, arrives later than the reflection from the base (Figure 7). Unlike a reflection and a refraction which converge at longer offsets, the high velocity of the Sewickley sandstone causes its top and bottom reflections to diverge.

The head wave traveling along the top of the Sewickley sandstone is the first energy to reach the surface at large offsets. However, this event (Event C, Figure 2) is represented by a relatively small-amplitude positive cycle that could easily be missed if the noise level were higher (see early arrivals on Figure 3, for example). The earliest observed arrivals in the noise test (Figure 2) are dominated by a negative event, interpreted to be the wide-angle reflection from the base of the Sewickley sandstone.

Considerable study has been devoted to the analysis of head-wave amplitudes (Heelan, 1953; O'Brien, 1955; Levin and Ingram, 1962). Červeny and Ravindra (1971) present calculations of head-wave amplitude versus of̂́set for a model with a refractive index and other contrasts in physical properties that are similar to those of the Sewickley sandstone in our model (Figure 6). Červeny and Ravindra's (1971. Figure 3.24) calculations reveal a rapid dropoff in head-wave amplitude relative to the corresponding wideangle reflection from the interface. Model studies presented by Press et al. (1954) reveal small-amplitude head waves relative to reflections from the base of the refracting layer. Levin and Ingram (1962), using duralumin and lucite layers, report the reflection amplitude from the base of the uppermost lucite layer to be 6.7 times greater than the head-wave amplitude across the top.

The amplitude of the head wave traveling along the top of the Sewickley sand was approximated using Heelan's (1953) theoretical relationship, which was verified experimentally by O'Brien (1955); the head-wave amplitude at the critical angle was calculated using Zoeppritz amplitude equations. The amplitude of the reflection from the base of the Sewickley sandstone was estimated by scaling the reflection coefficient by spherical divergence and two-way transmission losses across the upper boundary. All reflection and transmission coefficients in this paper were calculated using 
Zoeppritz equations. The calculated reflection-to-head-wave amplitude ratio is approximately $10: 1$ at the $150 \mathrm{ft}(46 \mathrm{~m})$ offset,

The actual relationship is complicated by the dominant frequency of the wavefront and relative thickness of the refracting layer (Press et al., 1954; Levin and Ingram, 1962), absorption, and scattering in the overburden (Press et al., 1954), and the presence of an abrupt or gradual velocity transition (Pilant, 1979). Velocity contrasts shown in Figure 1 are transitional in nature. Changes in the phase of the head wave are also expected (Kolsky, 1963), changes that distort the shape of the head wave as it travels along the interface.

Discrimination between the head wave and wide-angle reflections in this thinly bedded near-surface sequence is further complicated by the very small arrival-time difference between the two events. At the $150 \mathrm{ft}(46 \mathrm{~m})$ optimum offset, the computed head-wave arrival time is only $0.3 \mathrm{~ms}$ earlier than the computed reflection arrival time. At $230 \mathrm{ft}(70 \mathrm{~m})$. near the limit of usable offsets, the arrival time difference decreases to $0.15 \mathrm{~ms}$.

Given the small arrival-time difference, the estimated 10:1 reflection-to-head-wave amplitude ratio, and the transitional nature of the velocity variation at the top of the Sewickley sandstone, the early arrivals, even in a high signal-to-noise recording environment, are expected to be dominated by the wide-angle reflection from the base of this relatively thin layer. Winterstein and Hanten (1985) make similar observations for data recorded in the Midland Basin. One cannot always assume that the early arrivals observed in a noise test are simply isolated head waves.

Redstone and Pittsburgh coal reflections.-Further comparison of the synthetic seismogram (Figure 7) to the noise test (Figure 2) indicates that the Redstone and Pittsburgh coal reflections correspond to the negative cycles labeled D and $\mathrm{E}$, respectively. Because near-source reflection arrivals are obscured by linear noise, the Redstone coal reflection is linear and refraction-like in appearance. On the other hand, the Pittsburgh coal reflection is more nearly hyperbolic.

The synthetic seismogram of Figure 7 helps us interpret events on line 1 (Figure 4). Only limited data have been obtained from intervals above the mine in the Redstone coal. Interference between the shallower wide-angle reffections and the Redstone coal reflection and reduced interval traveltimes between reflection interfaces at nonzero offsets reduce the potential for resolving detail in this interval.

Although reflection events portrayed in the synthetic record at near-source offsets show considerably more detail (Figure 7), they are not usable in actual practice because high-amplitude near-source linear noise events dominate the near-source signal (Figures 2 and 3). Understanding the common-offset response of these shallow intervals clearly requires the use of nonzero-offset synthetic seismograms.

\section{Line 2}

The noise test shown in Figure 3 was collected along line 2 of Figure 5. At this location, the Redstone coal, which was unmined at the time of this survey, was approximately $212 \mathrm{ft}$ $(65 \mathrm{~m})$ deep. A synthetic shot record constructed using the subsurface acoustic properties defined in Figure 1 is presented in Figure 8. As in Figure 7, the slow, near-surface, wide-angle reflection events have been excluded from the synthetic record (Figure 8) to produce a more accurate representation of events observed at the $150 \mathrm{ft}(46 \mathrm{~m})$ offset (Figure 3).

As discussed above for line 1, the high-amplitude refraction-like event with a leading negative cycle observed at the $150 \mathrm{ft}(46 \mathrm{~m})$ offset (Figure 8$)$ is a composite of several wide-angle reflections. The reciprocal slope of the event on the synthetic is approximately $12000 \mathrm{ft} / \mathrm{s}(3660 \mathrm{~m} / \mathrm{s})$, which is close to the $12250 \mathrm{ft} / \mathrm{s}(3730 \mathrm{~m} / \mathrm{s})$ measured on the field data (Figure 3). The low-amplitude positive cycle preceding

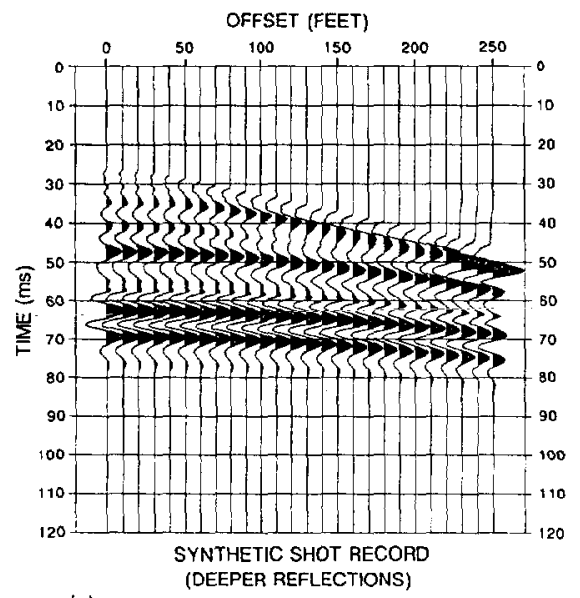

(a)

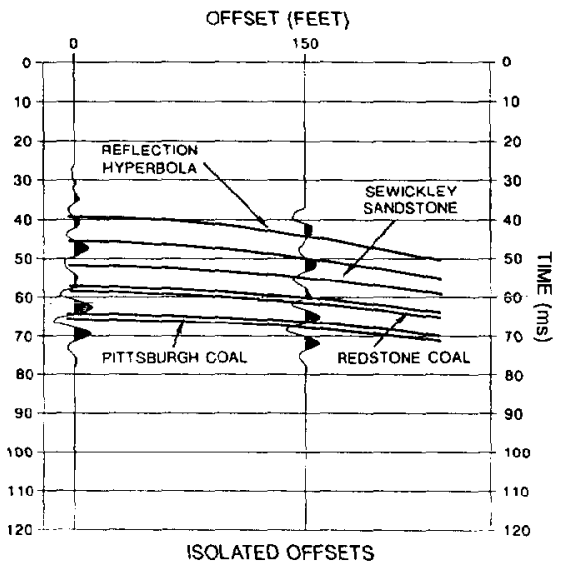

(b)

FIG. 8. (a) Synthetic shot record calculated for primary reffections only using the line 2 model (Figure 1). Zoeppritz equations were used to calculate reflection amplitude. Reflections from near-surface intervals have been excluded. (b) Synthetic seismic response at the zero and $150 \mathrm{ft}(46 \mathrm{~m})$ optimum offsets are isolated for comparison. Selected reflection hyperbolas are highlighted. 
the high-amplitude negative cycle between offsets of 100 and $170 \mathrm{ft}(31$ and $52 \mathrm{~m}$ ) on Figure 3 may be a refraction.

Based on the synthetic record (Figure 8), reflection events on the common-offset section (Figure 5) and the noise record (Figure 3) can easily be correlated to stratigraphic intervals such as the Sewickley sandstone and the Redstone and Pittsburgh coals. These intervals are deeper along line 2 than along line 1, and their appearance is much less affected by the numerous shallow wide-angle reflection events.

\section{NORMAL-INCIDENCE MODELING}

For the synthetic records (Figures 7 and 8), Poisson's ratios (Figure 1) were chosen to approximate closely the amplitude variations with incidence angle that are significant, particularly for the shallower reflections. Reflection amplitudes vary less with offset for the deeper reflections (Figure 8), since the range of incidence angles is much smaller. Along line 2, the Sewickley sandstone is much deeper [140 $\mathrm{ft}(43 \mathrm{~m})]$ than along line 1 . The angle of incidence of the reflection from the base of the Sewickley sandstone at the $150 \mathrm{ft}(46 \mathrm{~m})$ off set is only 36 degrees along this line, compared to 72 degrees along line 1. Calculations indicate that the amplitude of the Sewickley sandstone reflection at $150 \mathrm{ft}(46 \mathrm{~m})$ is only 25 percent less than that at zero offset.

The line 2 synthetic shot record (Figure 8) shows major variations in response for reflection events from interfaces shallower than $100 \mathrm{ft}(30 \mathrm{~m})$, or approximately two-thirds of the common-offset distance. Shallower reflections converge rapidly at the longer offsets, causing reflection interference and considerable change in the composite response.

The zero- and $150 \mathrm{ft}(46 \mathrm{~m})$ offset traces are isolated for comparison in Figure 8b. Reflection hyperbolas from a shallow [104 ft ( $32 \mathrm{~m}$ ) deep] interface, the top and base of the Sewickley sandstone, and the Redstone and Pittsburgh coals are highlighted. Only minor changes occur in the synthetic response of the Sewickley sandstone-Pittsburgh coal interval as the offset increases to $150 \mathrm{ft}(46 \mathrm{~m})$, indicating that the seismic response of intervals deeper than $100 \mathrm{ft}(30 \mathrm{~m})$ can be

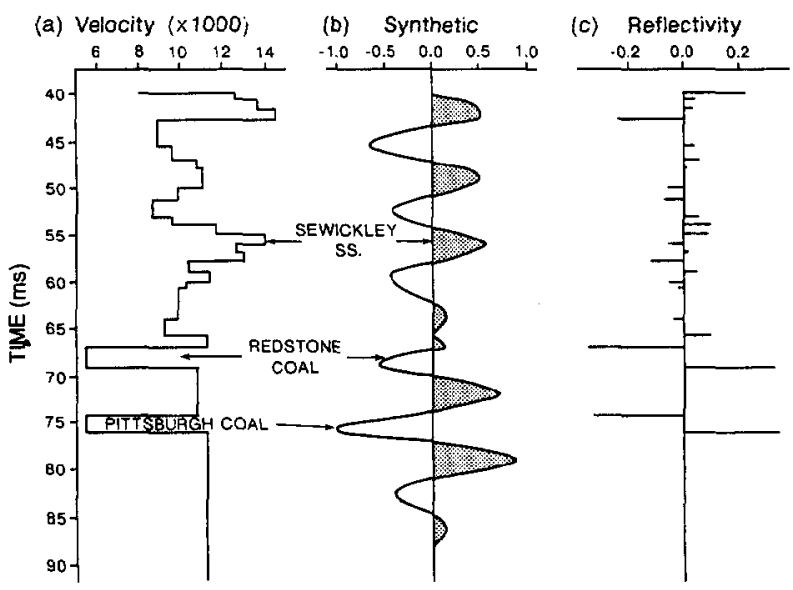

Fig. 9. Zero-offset synthetic seismogram. (a) Interval velocity. (b) Synthetic seismic trace. (c) Reflectivity sequence. modeled using simpler and less time-consuming zero-offset synthetic seismograms.

A normal-incidence (zero-offset) synthetic seismogram is presented in Figure 9. For the deeper part of the log (greater than $70 \mathrm{ft}$ ), this synthetic trace allows one to correlate events observed in the seismic data (Figures 3 and 5) with subsurface stratigraphic intervals observed in the borehole. The impedance contrast across the upper layer in the model (at $40 \mathrm{~ms}$ ) has been arbitrarily adjusted to simulate the composite wide-angle response at this offset.

The synthetic trace of Figure 9 is repeated four times in Figure 10 and is compared to traces 57 through 60 close to the borehole. The Sewickley sandstone and the Redstone and Pittsburgh coal seams form recognizable reflection events in the common-offset data. However, the seismic response from the interval between the Sewickley sandstone and Redstone coal is variable across much of the line (Figure 5). Reflection amplitude is generally weaker in the Sewickley-to-Redstone interval and the influence of noise is more noticeable. Variations of absorption in the near surface also have a greater effect on the amplitude and bandwidth of reflections from this interval. Consequently, the model wavelet of Figure 2, derived from an average autocorrelation, is generally only an approximation of the actual wavelet at any one place along the line.

Since the bandwidth of the data in this area is slightly lower than the bandwidth of the model wavelet, a 50 to 200 $\mathrm{Hz}$ band-pass (sixth-order Butterworth) filter was applied to it to produce the synthetic traces plotted for comparison with the actual data in Figure 10. The filtered synthetic compares well with trace 60 ; however, the noisy character of the data permits only general identification of the Sewickley sandstone and Redstone and Pittsburgh coals in this area. Poor geophone coupling related to the presence of thicker near-surface soils on the right end of the line is largely responsible for the poor quality of the data in this area.

Interval velocities in the model (Figure 9) were reduced by an average of 10 percent so that the relative arrival times of

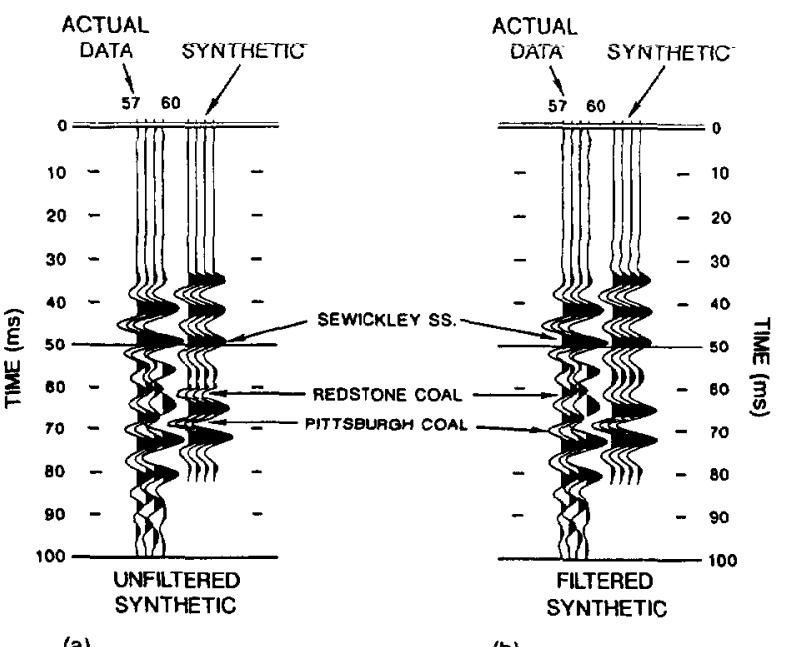

(a)

(b)

Fig. 10. The zero-offset synthetic seismogram (Figure 9) compared to traces 57 through 60 near the borehole on line 2. (a) Unfiltered; (b) filtered. 
the Sewickley sandstone and Pittsburgh coal events would match those observed in the data near the borehole (Figures 5 and 10 ). This difference in velocity may be related to the larger Fresnel zone of the seismic waveform compared to that of the sonic logging tool. A much larger volume of rock is sampled by the seismic waveform. The reduced interval velocity, along with the disagreement between some of the details of the synthetic and the actual data, may indicate that the acoustic properties of the Sewickley-to-Redstone interval inferred from the sonic $\log$ are not representative of the larger rock volume sampled by the surface-generated seismic waveform.

Line 2 (Figure 5) also reveals the presence of a $5 \mathrm{~ms}$ increase in the Sewickley-to-Pittsburgh interval traveltime between traces 15 to 60 . However, only $5 \mathrm{ft}$ of structural relief (based on mine maps and surrounding borehole data) accounting for a $1 \mathrm{~ms}$ increase in interval traveltime is present along the line in the form of regional dip. Hence, the $5 \mathrm{~ms}$ difference is probably related to a gradual decrease in the average velocity of this interval. The reduction in average velocity may be related to an increase of fracture intensity and/or weathering of these intervals, as the line runs from a narrow gulley on the left to a more exposed hillside on the right (Figure 5).

Interesting character changes are observed in the Sewickley reflection event, illustrated, for example, on traces 41 through 47 (Figure 5). An explanation for this change in seismic character is suggested by the velocity model in Figure 11. The Sewickley sandstone lies deeper in the section and is several feet thinner than in Figure 9a. The Sewickley sandstone is a channel sand, and scouring by the channel could have placed it deeper in the section (Donaldson et al., 1979). The response of this model (Figure 11) compared to traces 41 through 47 (Figure 12) shows the general character of the Sewickley sandstone reflection event to be well approximated by the synthetic record. The synthetic was filtered as in Figure 10b. Interval traveltimes between the Sewickley sandstone and Redstone and Pittsburgh coals are less in the data than in the synthetic (Figure 12), because of the reduction of average velocity in these
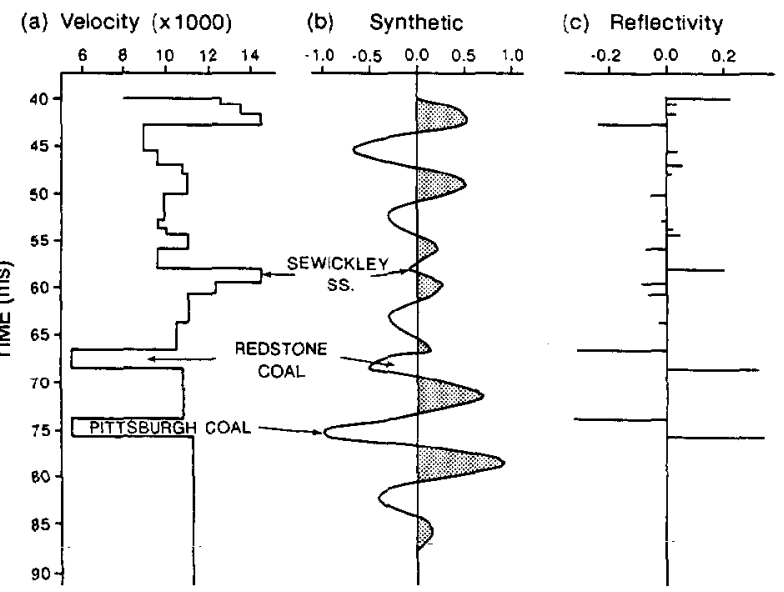

FiG. 11. (a) Modified interval velocity versus time. (b) Zero-offset synthetic seismic response. (c) Modified reflectivity sequence. intervals mentioned above. Variable scouring of the sandstone into the underlying formations may contribute to this observed thinning.

Other changes in the character of reflections in the Sewickley-to-Redstone interval observed along line 2 (Figure 5) may be related to nonstationarity in the seismic wavelet resulting from spatial and time-variable differences in absorption and scattering or simply to noise in the data.

\section{CONCLUSIONS}

Common-offset synthetic seismograms are often required to understand the origins and significance of events observed in a common-offset profile. Offset model studies suggest the following:

(1) Significant absorption attenuates the direct arrival and wide-angle reflections that arise in the upper 20 to $25 \mathrm{ft}(6$ to $8 \mathrm{~m}$ ) of the near surface in the study area. Otherwise, these events would produce significant interference with reflections from the zone of interest at the $150 \mathrm{ft}$ ( $46 \mathrm{~m}$ ) optimum offset.

(2) The highly absorptive near-surface interval effectively eliminates significant near-surface-generated multiples from the downgoing wave field.

(3) The early arrivals at this site are interpreted to be dominated by wide-angle reflections rather than head waves. On the $150 \mathrm{ft}(46 \mathrm{~m})$ offset used to collect the data presented here, wide-angle reflections from impedance contrasts in the upper 80 to $100 \mathrm{ft}(24$ to $30 \mathrm{~m}$ or approximately two-thirds the common-offset distance) converge to form a composite refraction-like event. Dominance of the early arrivals by wide-angle reflections allows one to simulate the common-offset response at this site using reflections-only calculations. The relationship needs to be evaluated on a site-by-site basis.

(4) Variations in reflection amplitude with incidence angle are significant for reflections from depths less

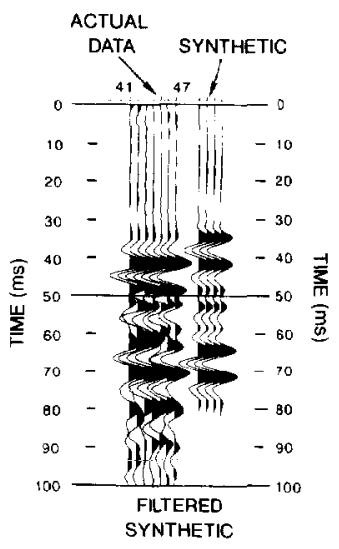

FIG. 12. Comparison of synthetic (Figure 11b) to traces 41 through 47 (line 2). 
than two-thirds of the common offset but become less significant at this site as depth increases and the range of incidence angles decreases.

(5) Below a depth of approximately two-thirds the optimum-offset distance, the zero-offset response is very similar to that observed at the optimum offset, so that the seismic response of the deeper intervals in the study area could be simulated using normal-incidence calculations.

In general these studies indicate that information about the stratigraphic character of the near-surface Paleozoic rocks of the study area can be obtained from common-offset seismic data.

\section{ACKNOWLEDGMENTS}

This work was undertaken under Task 2 of a multitask project titled "An Improved Longwall Mining Technique" funded by the West Virginia University's Energy and Water Research Center and coordinated by Syd Peng.

Reviews of the paper by Don Steeples, Mike Schoenberger, and anonymous GEOPHysics reviewers were greatly appreciated. The author thanks Paul Bork, Bill Hasslebacher, Robert C. Shumaker, Henry Rauch, Alan Donaldson, Brian Herridge, Guoqi He, Li Zheng, and Tom Taylor for field assistance and/or discussions related to the problems presented here. Thanks also to Paul Sutter and Randy Crowe (WVU Dept. of Geology) for computer system and software assistance, and Alison Hanham for her work with the illustrations in the paper.

Special thanks to Paul Bork of Bison Instruments Inc. for supervising the acquisition of the data presented in this paper. His efforts resulted in what those who reviewed the paper and I feel are excellent shallow data.

The author also extends appreciation to GeoQuest International Inc. of Houston, Texas for use of their AIMS III (Advanced Interpretive Modeling System) software. All the offset simulations were generated using AIMS III.

\section{REFERENCES}

Cerveny, V., and Ravindra, R., 1971, Theory of seismic head waves: Univ. of Toronto Press.

Dobecki, T. L., and Larson, D. M., 1987, Seismic detection of abandoned coal mine workings: Proc., 28th U.S. Sympos. on Rock Mechanics, 57-64.

Dobecki, T. L., and Romig, P. R., 1985, Geotechnical and groundwater geophysics: Geophysics, 50, 2621-2636.

Donaldson, A., Presley, M. W., and Renton, J. J., 1979, Carboniferous coal guidebook: West Virginia Geologic and Economic Surv., Bull. B-37-1 through 3.

He, G., and Wilson. T. H., 1989, Changes in the seismic properties of the cover produced by longwall mining: Proc., 30th U.S. Sympos. on Rock Mechanics, 327-334.

Heelan, P. A., 1953, On the theory of head waves: Geophysics, 18, $871-893$.

Hunter, J. A., and Pullan, S. E., 1989, The optimum offset shallow seismic reflection technique: Proc., Symp. on the Application of Geophysics to Engineering and Environmental problems, Soc. Engr. and Min. Expl. Geophys., 143-174.

Hunter, J. A., Pullan, S. E., Burns, R. A., Gagne, R. M., and Good, R. L., 1984, Shallow reflection mapping of the overburdenbedrock interface with the engineering seismograph-Some simple techniques: Geophysics, 49, 1381-1385.

1985, The optimum offset shallow reflection technique: case histories: 55th Ann. Internat. Mtg., Soc. Expl. Geophys, Expanded Abstracts, 159-161.

Kolsky, H., 1963, Stress waves in solids: Dover Publ. Inc.

Levin, F. K., and Ingram, J. D., 1962, Head waves from a bed of finite thickness: Geophysics, 27, 753-765.

O'Brien, P. N. S., 1955, Model seismology-the critical refraction of elastic waves: Geophysics, 20, 227-242.

Pilant, W. L., 1979, Elastic waves in the earth: Elsevier Sci. Publ. Co.

Press, F., Oliver, J., and Ewing, M., 1954, Seismic model studies of refraction from a layer of finite thickness: Geophysics, 19, 388401.

Rzhevsky, V., and Novik, G., 1971, The physics of rocks: MIR Publ.

Sheriff, R. E., 1977, Limitations on resolution of seismic reflections and geologic detail derivable from them, in Peyton, Ed., Seismic stratigraphy-Applications to hydrocarbon exploration: AAPG Memoir 26, 3-14.

Szelwis, R., and Behle, A., 1987, Shallow shear-wave velocity estimation from multimodal Rayleigh waves, in Danbom, S. H., and Domenico, S. N., Eds., Shear-wave exploration: Soc. Expl. Geophys., 214-226.

Widess, M. B., 1973, How thin is a thin bed?: Geophysics, 38, $1176-1180$.

Wilson, T. H., He, G., and Haslebacher, W., 1988, Seismic studies over active longwall mines: Proc. 7th Internat. Conf. on Ground Control and Mining, 289-302.

Winterstein, D. F., and Hanten, J. B., 1985, Supercritical reflections observed in $P$ - and $S$-wave data: Geophysics, 50, 185-195. 